\title{
Acute injury in the peripheral nervous system triggers an alternative macrophage response
}

\author{
Elke Ydens ${ }^{1}$, Anje Cauwels ${ }^{2,3}$, Bob Asselbergh ${ }^{1}$, Sofie Goethals ${ }^{1}$, Lieve Peeraer ${ }^{1}$, Guillaume Lornet ${ }^{3,4}$, \\ Leonardo Almeida-Souza ${ }^{1}$, Jo A Van Ginderachter ${ }^{5,6}$, Vincent Timmerman ${ }^{1^{*}}$ and Sophie Janssens ${ }^{3,4^{*}}$
}

\begin{abstract}
Background: The activation of the immune system in neurodegeneration has detrimental as well as beneficial effects. Which aspects of this immune response aggravate the neurodegenerative breakdown and which stimulate regeneration remains an open question. To unravel the neuroprotective aspects of the immune system we focused on a model of acute peripheral nerve injury, in which the immune system was shown to be protective.

Methods: To determine the type of immune response triggered after axotomy of the sciatic nerve, a model for Wallerian degeneration in the peripheral nervous system, we evaluated markers representing the two extremes of a type I and type II immune response (classical vs. alternative) using real-time quantitative polymerase chain reaction (RT-qPCR), western blot, and immunohistochemistry.

Results: Our results showed that acute peripheral nerve injury triggers an anti-inflammatory and immunosuppressive response, rather than a pro-inflammatory response. This was reflected by the complete absence of classical macrophage markers (iNOS, IFNy, and IL12p40), and the strong up-regulation of tissue repair markers (arginase-1, Ym1, and Trem2). The signal favoring the alternative macrophage environment was induced immediately after nerve damage and appeared to be established within the nerve, well before the infiltration of macrophages. In addition, negative regulators of the innate immune response, as well as the anti-inflammatory cytokine IL-10 were induced. The strict regulation of the immune system dampens the potential tissue damaging effects of an over-activated response.

Conclusions: We here demonstrate that acute peripheral nerve injury triggers an inherent protective environment by inducing the M2 phenotype of macrophages and the expression of arginase-1. We believe that the M2 phenotype, associated with a sterile inflammatory response and tissue repair, might explain their neuroprotective capacity. As such, shifting the neurodegeneration-induced immune responses towards an M2/Th2 response could be an important therapeutic strategy.
\end{abstract}

Keywords: Innate immune system, Negative regulation, M2, RT-qPCR, Neuroprotection, Wallerian degeneration

\section{Background}

Injury to the peripheral nervous system (PNS) induces a well-orchestrated cellular process that leads to the complete disintegration of the nerve segment distal to the lesion site, termed Wallerian degeneration (WD) [1].

\footnotetext{
* Correspondence: vincent.timmerman@molgen.vib-ua.be; sophie.janssens@ dmbr.vib-ugent.be

${ }^{1}$ Peripheral Neuropathy Group, Department of Molecular Genetics, VIB and University of Antwerp, Antwerpen, Belgium

${ }^{4}$ GROUP-ID Consortium, Laboratory for Immunoregulation and Mucosal Immunology, GhentUniversity, Ghent, Belgium

Full list of author information is available at the end of the article
}

As axons are disconnected from their cell bodies, they are rapidly fragmented by an intrinsic active process of self-destruction [2]. Due to the loss of axonal contact, the myelinating Schwann cells (SC) dedifferentiate into an immature phenotype, start proliferating, and help in the degeneration of myelin. Wallerian degeneration typically triggers a strong neuroinflammatory response in which the SCs are believed to play an important role. Being in close contact with the nerves, SCs are among the first to respond to nerve damage. They induce the production of pro-inflammatory cytokines such as TNF, IL-1 $\alpha$, and IL-1 $\beta$ within hours after nerve injury [3-5].

\section{Biomed Central}


Subsequently, these cytokines induce the expression of additional immune mediators such as IL-6, GM-CSF, and IL-10 in both Schwann cells and fibroblasts $[3,4,6,7]$. The production of MCP-1 and MIP- $1 \alpha$, which reaches a maximum at 1 day after injury, promotes the recruitment of macrophages to the damaged nerves $[4,8]$. Moreover, mast cells accumulate in the endoneurium of injured nerves [9] and release mediators that contribute to the recruitment of macrophages and neutrophils $[9,10]$. Infiltration of blood-borne monocytes, which spread over the entire nerve, starts from 2 to 3 days after injury and macrophage accumulation peaks at 7 days post injury [11-14]. These infiltrated immune cells take over the cytokine production and are responsible for the rapid clearance of myelin debris. Before the infiltration of hematogenous macrophages, local macrophages proliferate and undergo morphological changes consistent with immunophenotypic signs of activation [15]. These resident macrophages, together with SCs, readily contribute to myelin phagocytosis [12,16]. Two to three weeks after injury, the inflammatory response is turned off and macrophages are rapidly eliminated $[12,13,17]$. Generally, WD is believed to induce a strong pro-inflammatory response, as reflected by the induction of cytokines such as TNF and IFN $\gamma$ [18-20], and the reported elevation of iNOS [21]. Still, one would expect that neurodegeneration might trigger a more dampened immune response, which is typically associated with sterile inflammation. To address this question we used a model of WD (axotomy of the sciatic nerve) to analyze which type of immune response is being induced. Our results revealed that WD leads to the expression of several negative regulators of the innate immune system. In addition, a predominant M2-like macrophage response could be observed, reflecting the presence of an immunosuppressive milieu necessary to initiate wound repair and restore tissue homeostasis.

\section{Material and methods}

\section{Mice work and induction of peripheral nerve injury}

All animal experiments were approved by the local ethics committee (University of Antwerp), and conducted according to the guidelines of the Federation of European Laboratory Animal Science Associations (FELASA). Axotomy experiments of the $N$. ischiadicus (sciatic nerve) were conducted in 6- to 8-week-old C57BL/6 mice as previously described [22]. Briefly, mice were anesthetized with a single intraperitoneal injection of ketamine (Ketalar; Pfizer; $150 \mathrm{mg} \mathrm{kg}^{-1}$ ) and xylazine (Rompun; Bayer; $10 \mathrm{mg} \mathrm{kg}^{-1}$ ). An incision was made at the right thigh, and gluteal and hamstring muscles were carefully separated to expose the sciatic nerve. The sciatic nerve was transected and the wound was closed by sutures. The contralateral side was left untouched. For analgesia, bupronorphinum (Temgesic; Schering-Slough; 0,1 mg kg-1) was injected after surgery. Sham operation experiments were performed to evaluate the effect of damage around the nerve, inflicted by the operation, on the gene expression profile.

\section{Intravenous injection of TLR ligands}

Lipopolysaccharide (LPS; TLR4-ligand) (Sigma; $10 \mathrm{mg} \mathrm{kg}^{-1}$ ) or triacyl lipopeptide (Pam3Cys; TLR1/2-ligand) (Sigma; $10 \mathrm{mg} \mathrm{kg}^{-1}$ ) were injected intravenously in 6- to 8-week-old C57BL/6 mice. PBS was injected in the control mice.

\section{RNA isolation and RT-qPCR}

At defined time points after sciatic nerve transection, the mice were euthanized by inhalation of $\mathrm{CO}_{2}$. The distal part of the transected $N$. ischiadicus and the contralateral control side were removed; snap frozen and stored at $-80{ }^{\circ} \mathrm{C}$ until use. The nerves were homogenized in Trizol with a Potter Elvehjem homogenisator, and small fragments were further homogenized by sonication. Total RNA was extracted using the RNeasy Lipid Tissue kit (Qiagen) according to the manufacturer's protocol. The quality of the RNA was verified by gel electrophoresis. DNase treatment was performed with TURBO DNase (Ambion). cDNA was produced using the Superscript III first strand synthesis system for RTPCR (Invitrogen). Real-time quantitative polymerase chain (RT-qPCR) reactions were done with $10 \mathrm{ng}$ cDNA in SYBR Green I mix and run on an ABI Prism 7900 HT Sequence Detection System (Applied Biosystems). All PCR reactions were performed in triplicate. Primers were designed making use of Primerbank (www.pga. mgh.harvard.edu/primerbank). Primer sequences are listed in Table 1. The RT-qPCR data were normalized according to the method described by Vandesompele et al. [23], by geometric averaging of multiple internal control genes. Processing the raw data and normalization of the relative quantities were computed with an improved version of the $\Delta \Delta$-Ct-method [24]. The mRNA expression levels are expressed relative to the basal condition (0 h time point; not operated mice or not injected mice).

\section{Cell isolation}

As a control for the western blot analysis, peritoneal macrophages were stimulated to induce the M1 or M2 expression profile. Peritoneal macrophages were isolated from adult mice that were injected with $3 \%$ thioglycollate [25]. On day 4 after injection, mice were euthanized and the peritoneal cavity rinsed with ice-cold PBS. Macrophages were collected and resuspended in RPMI with $1 \%$ FCS. Erythrocytes stayed in suspension and were removed after $45 \mathrm{~min}$. The remaining cells were kept in RPMI with 10 \% FCS. The next day, dendritic cells in suspension were removed and macrophages were 


\section{Table 1 Primer sequences}

\begin{tabular}{|c|c|c|}
\hline \multicolumn{3}{|c|}{ Negative regulators } \\
\hline $\mathrm{A} 20$ & GAACAGCGATCAGGCCAGG & GGACAGTTGGGTGTCTCACATT \\
\hline $\mathrm{IkBa}$ & TGAAGGACGAGGAGTACGAGC & TTCGTGGATGATTGCCAAGTG \\
\hline IL-1RA & GCTCATTGCTGGGTACTTACAA & CCAGACTTGGCACAAGACAGG \\
\hline MyD88s & TGAAGTCGCGCATCGGAC & CGGCGACACCTITTCTCAAT \\
\hline SIGIRR & GTGACATGGCCCCTAATTTCC & ATGCCAGACCATCTTTCAGCC \\
\hline SOCS1 & CTGCGGCTTCTATTGGGGAC & AAAAGGCAGTCGAAGGTCTCG \\
\hline \multicolumn{3}{|c|}{ Immune mediators } \\
\hline Cox2 & TGAGCAACTATTCCAAACCAGC & GCACGTAGTCTTCGATCACTATC \\
\hline MIP-1a & TTCTCTGTACCATGACACTCTGC & CGTGGAATCTTCCGGCTGTAG \\
\hline $\operatorname{IL} 1 \beta$ & GCAACTGTTCCTGAACTCAACT & ATCTIITGGGGTCCGTCAACT \\
\hline IL6 & TAGTCCTTCCTACCCCAATTTCC & TTGGTCCTTAGCCACTCCTTC \\
\hline MCP-1 & TTAAAAACCTGGATCGGAACCAA & GCATTAGCTTCAGATTTACGGGT \\
\hline \multicolumn{3}{|c|}{ Macrophage markers and M1/M2 markers } \\
\hline AlF1/Iba1 & ATCAACAAGCAATTCCTCGATGA & CAGCATTCGCTTCAAGGACATA \\
\hline $\operatorname{Arg} 1$ & TGGCTTGCGAGACGTAGAC & GCTCAGGTGAATCGGCCTIIT \\
\hline CD11b & CCATGACCTTCCAAGAGAATGC & ACCGGCTTGTGCTGTAGTC \\
\hline Cdh1 & GTCTACCAAAGTGACGCTGAA & GGGTACACGCTGGGAAACAT \\
\hline $\mathrm{F} 4 / 80$ & ATGGACAAACCAACTITCAAGGC & GCAGACTGAGTTAGGACCACAA \\
\hline $\mathrm{FIZZ1}$ & CCAATCCAGCTAACTATCCCTCC & ACCCAGTAGCAGTCATCCCA \\
\hline IFNY & ATGAACGCTACACACTGCATC & CCATCCTITTGCCAGTTCCTC \\
\hline$\underline{\mathrm{IL} 4}$ & GGTCTCAACCCCCAGCTAGT & GCCGATGATCTCTCTCAAGTGAT \\
\hline IL10 & ATGGCCGGATAGCCTTATTC & ACGATGTGGTGACAACCGTA \\
\hline IL 12p40 & AGTGTGAAGCACCAAATTACTCC & CCCGAGAGTCAGGGGAACT \\
\hline IL-13 & GCAACATCACACAAGACCAGA & GTCAAGGAATCCAGGGCTAC \\
\hline iNOS & GTTCTCAGCCCAACAATACAAGA & GTGGACGGGTCGATGTCAC \\
\hline MRC1 & CTCTGTTCAGCTATTGGACGC & CGGAATTTCTGGGATTCAGCTTC \\
\hline TREM2 & GAACCGTCACCATCACTCTGA & CCTCGAAACTCGATGACTCCT \\
\hline Ym1 & AGAAGGGAGTTTCAAACCTGGT & СTCTTGCTGATGTGTGTAAGTGA \\
\hline IFNYR1 & GTGGAGCTITGACGAGCACT & ATTCCCAGCATACGACAGGGT \\
\hline$\underline{I L} 4 \mathrm{Ra}$ & ATITGCTGTTGGTGACTGGA & CGTGGAAGTGCGGATGTAGT \\
\hline IL10R & CCTATCCCAAACCAGTCTGAGA & CCAGGTTGAGTTTCCGTACTGT \\
\hline IL13Ra1 & TCAGCCACCTGTGACGAATTT & TGAGAGTGCAATTTGGACTGG \\
\hline \multicolumn{3}{|c|}{ Scavenger receptors } \\
\hline Clec7a & ATTTGGCGACACAATTCAGGG & GCAAGACTGAGAAAAACCTCCT \\
\hline Rage & ATGCACAGAAACGGGATCTIT & CTGCTTGGAATAGACACTCCG \\
\hline \multicolumn{3}{|c|}{ Housekeeping genes } \\
\hline ACTB & GCTTCTAGGCGGACTGTTACTGA & GCCATGCCAATGTTGTCTCTTAT \\
\hline B2M & ATGCACGCAGAAAGAAATAGCAA & AGCTATCTAGGATATTTCCAATTTTTGAA \\
\hline $\mathrm{HMBS}$ & GAAACTCTGCTTCGCTGCATT & TGCCCATCTITCATCACTGTATG \\
\hline RPL13a & CCTGCTGCTCTCAAGGTTGTT & TGGTTGTCACTGCCTGGTACTT \\
\hline$\overline{\mathrm{TBP}}$ & TCTACCGTGAATCTTGGCTGTAAA & TTCTCATGATGACTGCAGCAAA \\
\hline
\end{tabular}


kept in culture in RPMI with 10 \% FCS. Macrophages were stimulated with either LPS (Sigma; $100 \mathrm{ng} \mathrm{ml}^{-1}$ ) and IFNY (R\&D Systems; $100 \mathrm{ng} \mathrm{ml}^{-1}$ ) or IL-4 (R\&D Systems; $10 \mathrm{ng} \mathrm{ml}^{-1}$ ) and IL-13 (R\&D Systems; $10 \mathrm{ng} \mathrm{ml}^{-1}$ ) to generate M1 or M2 macrophages, respectively.

\section{Western blot analysis}

For western blot analysis, the distal part of the transected $N$. ischiadicus and the contralateral control side were carefully removed; snap frozen and stored at $-80^{\circ}$ $\mathrm{C}$ until use. Protein lysates were prepared in E1A lysis buffer (1\% NP-40, $20 \mathrm{mM}$ HEPES (pH 7.9), $250 \mathrm{mM}$ $\mathrm{NaCl}, 20 \mathrm{mM} \beta$-glycerophosphate, $10 \mathrm{mM} \mathrm{NaF}, 1 \mathrm{mM}$ sodium orthovanadate, $2 \mathrm{mM}$ dithiothreitol, $1 \mathrm{mM}$ EDTA, and a protease inhibitor cocktail) by homogenization in a Potter Elvehjem homogenisator. Total protein concentration was determined by Bradford. Equal amounts of protein lysates (20 to $30 \mu \mathrm{gram}$ ) were separated on NuPAGE gels, transferred to nitrocellulose membranes and analyzed by immunoblotting. Briefly, membranes were blocked using blocking buffer (5\% milk in PBS containing $0.1 \%$ Tween-20), and incubated overnight at $4{ }^{\circ} \mathrm{C}$ with a primary antibody. Secondary HRP-conjugated antibodies were used to visualize antibody signals on films using the ECL system (Thermo Scientific). Antibodies used were anti-arginase-1 (Santa

\section{a Cytokines and chemokines}
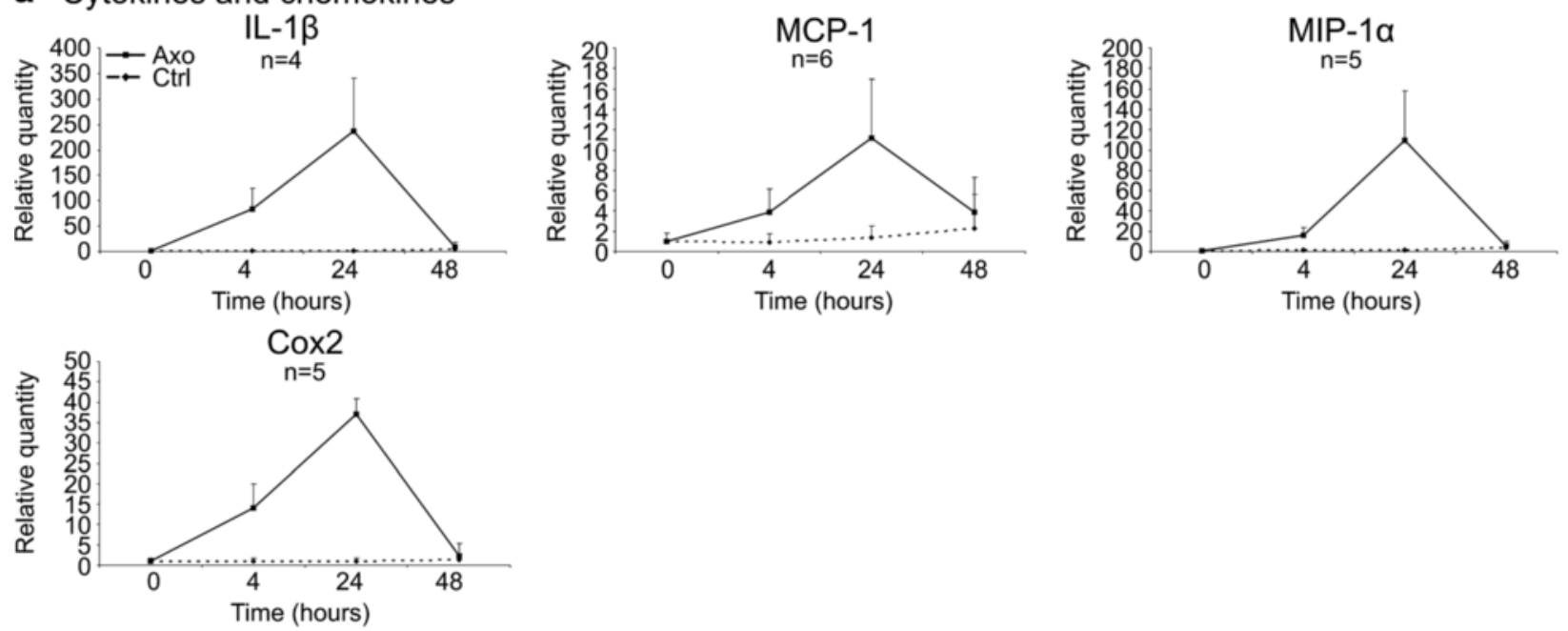

\section{b Negative regulators}
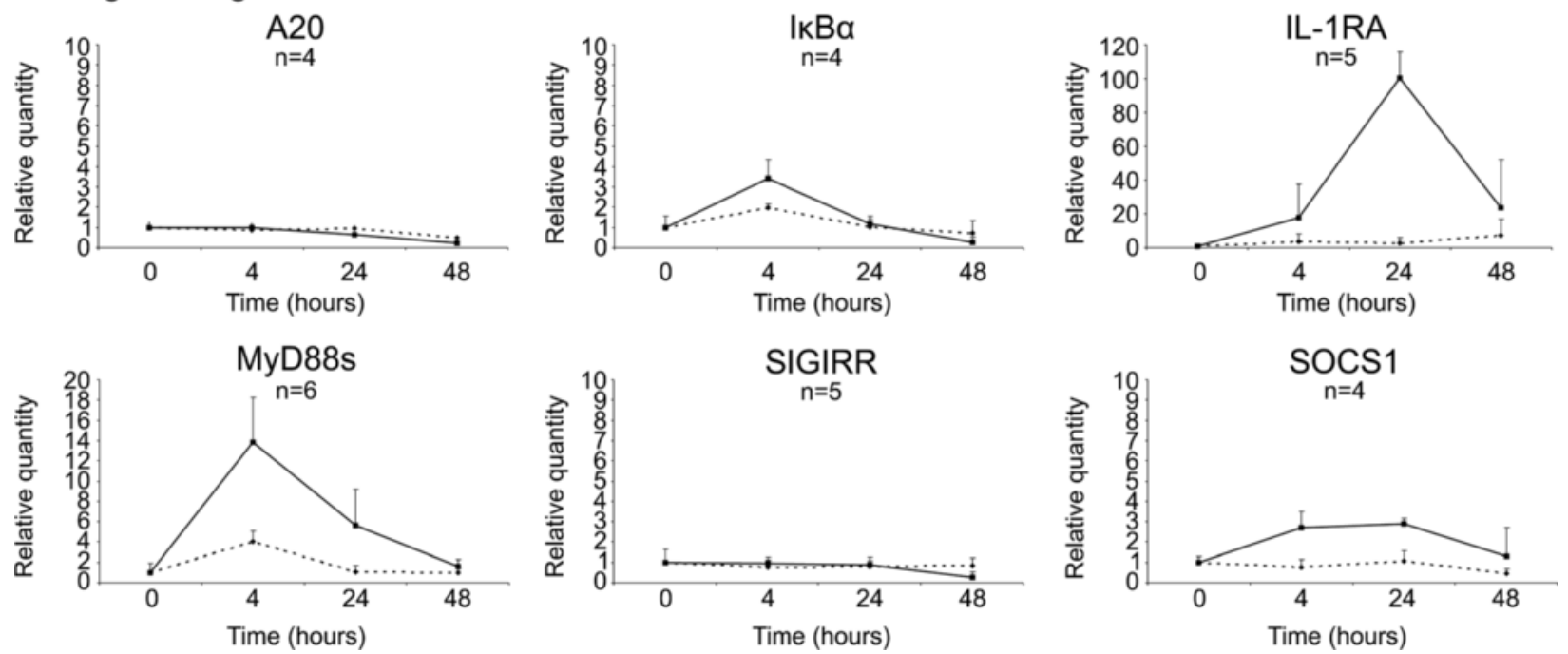

Figure 1 Peripheral nerve injury triggers a transient immune response. RT-qPCR analysis showing the transient induction of immune mediators at different time points after peripheral nerve injury (a), and the induction of negative regulators of the innate immune response (b), as determined by RT-qPCR analysis. RT-qPCR data are analyzed using the $\Delta \Delta$-Ct method and mRNA expression levels are expressed relative to the basal condition ( $=0 \mathrm{~h}$ time point). Data presented are the compiled data of different independent experiments, with $\mathrm{n}$ representing the number of independent experiments for each gene. 
Cruz; 1/1,000), anti-iNOS (BD Transduction Laboratories; $1 / 1,000)$ and anti- $\beta$-tubulin (Abcam; 1/10,000).

\section{Immunohistochemistry}

The dissected distal part of the sciatic nerve was fixed overnight in Bouin's fixative (saturated picric acid, formaldehyde, and glacial acetic acid). The nerves were dehydrated, embedded in paraffin for longitudinal sectioning, and stored until processing. The $4 \mu \mathrm{m}$ sections were immunohistochemically stained using the avidinbiotin staining technique. Briefly, slides were rehydrated and antigen retrieval was performed by boiling the slides in a citrate buffer (0.1 M sodium citrate buffer; $\mathrm{pH}$ 6.0). Endogenous peroxidase activity was blocked by treating the slides with $2 \%$ hydrogen peroxide for $20 \mathrm{~min}$. Next, the slides were incubated for $30 \mathrm{~min}$ in blocking buffer (20 \% normal goat serum in PBS with $1 \%$ BSA) and incubated overnight with primary antibody at $4{ }^{\circ} \mathrm{C}$. The antibodies used were arginase-1 (Santa Cruz) and iNOS (BD Transduction Laboratories). Sections were treated with avidin-conjugated secondary antibodies for $30 \mathrm{~min}$ at room temperature before adding an avidin-biotin complex solution (Vector Laboratories) for $30 \mathrm{~min}$. The signal was visualized by incubating the sections with 3.3'-diaminobenzidine (DAB) in PBS containing $0.1 \%$ hydrogen peroxide. Negative control sections were handled the same way, but in the absence of primary antibody. All sections were counterstained with hematoxylin and dehydrated before mounting. Sections were analyzed with a standard light microscope (Zeiss
Axioskop with Olympus UC30 camera). For double immunofluorescence staining, the $4 \mu \mathrm{m}$ sections of paraffin-embedded sciatic nerves, which were processed for antigen retrieval as described above, were incubated in a blocking solution (1\% milk in PBS) for $30 \mathrm{~min}$ and incubated at $4{ }^{\circ} \mathrm{C}$ with goat-anti-arginase- 1 antibody (Santa Cruz). The next day, a donkey-anti-goat Alexa fluor 488 conjugated secondary antibody (Life Technologies) was applied. After stringent washing, the staining with the second marker was performed with the same procedure, using a marker for macrophages (F4/80; Santa Cruz) and a marker for Schwann cells (S100; Dako) and an Alexa fluor 594 conjugated secondary antibody (Life Technologies). Negative controls, excluding one or both of the primary antibodies, were included in the experiments. The immunofluorescence images were captured on a Zeiss LSM700 confocal microscope, using a $40 \times(1.3 \mathrm{NA})$ objective. Frame-byframe scanning with standard emission settings and excitation with a $488 \mathrm{~nm}$ or $555 \mathrm{~nm}$ diode laser was used to discriminate the two fluorophores.

\section{Results}

Wallerian degeneration (WD) induces an immune response that is considered to be predominantly proinflammatory by expressing several pro-inflammatory molecules such as TNF, IFN $\gamma$, and iNOS [19-21]. To confirm the pro-inflammatory environment, we isolated total RNA of the distal segment of four sciatic nerves isolated at different time points upon axotomy. We

Table 2 Overview of the main functions of immune mediators and negative regulators of the immune system

\begin{tabular}{|c|c|c|}
\hline \multicolumn{3}{|c|}{ Immune mediators } \\
\hline MCP-1 (CCL2) & $\begin{array}{l}\text { Monocyte chemoattractant } \\
\text { protein- } 1 \text { (CC-chemokine 2) }\end{array}$ & $\begin{array}{l}\text { Chemokine, emigration of monocytes from } \\
\text { bone marrow; monocyte recruitment [27] }\end{array}$ \\
\hline $\operatorname{cox} 2$ & Cyclo-oxygenase 2 & $\begin{array}{l}\text { Production of prostaglandins; vasodilatation, } \\
\text { inflammation, platelet disaggregation [28], neuropathic pain [29] }\end{array}$ \\
\hline $\mathrm{IL}-1 \beta$ & Interleukin-1 beta & $\begin{array}{l}\text { Pro-inflammatory cytokine; many biological functions: } \\
\text { up-regulation of adhesion molecules, influx of neutrophils, } \\
\text { induction of additional inflammatory mediators, } \\
\text { important in sterile inflammation [30] }\end{array}$ \\
\hline IL-6 & Interleukin 6 & $\begin{array}{l}\text { Pleiotropic cytokine; wide range of biological activities in } \\
\text { immune regulation, hematopoiesis, and inflammation [31] }\end{array}$ \\
\hline MIP-1a (CCL3) & $\begin{array}{l}\text { Macrophage inflammatory } \\
\text { protein } 1 \text { alpha (CC-chemokine 3) }\end{array}$ & Chemokine, recruitment of monocytes to the inflamed tissue [4] \\
\hline \multicolumn{3}{|c|}{ Negative regulators } \\
\hline $\mathrm{A} 20$ & - & $\begin{array}{l}\text { Negative regulator of TLR-signaling. Blocks TLR-mediated } \\
\text { signaling by blocking NFKB signaling [32] }\end{array}$ \\
\hline $\mathrm{IkBa}$ & Inhibitor kappa B alpha & $\begin{array}{l}\text { Inhibits NFkB signaling by masking the nuclear localization } \\
\text { signal, keeping NFkB in its inactive state [33] }\end{array}$ \\
\hline$\underline{\mathrm{IL}-1 \mathrm{RA}}$ & IL-1 receptor antagonist & Antagonist of IL-1; binds to IL-1R1 thereby blocking signaling [30] \\
\hline MyD88s & Myeloid differentiation 88 small & Antagonist of the adaptor protein MyD88 [26] \\
\hline SIGIRR & $\begin{array}{l}\text { Single immunoglobulin } \\
\text { IL-1R-related molecule }\end{array}$ & $\begin{array}{l}\text { Inhibits IL-1 signaling, orphan receptor of IL-1 family with } \\
\text { antagonistic properties [34] }\end{array}$ \\
\hline SOCS1 & Suppressor of cytokine signaling 1 & Suppression of cytokine signaling by inhibiting JAK tyrosine kinase [35] \\
\hline
\end{tabular}


analyzed three independent experiments and measured the expression of several cytokine and chemokine transcripts using RT-qPCR. In line with literature data, the inflammatory mediators IL-1 $\beta$, Cox 2 , MCP-1, and MIP$1 \alpha$ were strongly up-regulated, with maximum expression levels at $24 \mathrm{~h}$ after axotomy (Figure 1a) [4]. Strikingly, the expression levels of the inflammatory genes dropped at later time points after axotomy, with most pro-inflammatory genes returning to the basal condition at $48 \mathrm{~h}$. We determined whether this transient immune response was accompanied with the induction of several negative regulators of the immune system and found that IL-1RA displayed a high induction (Figure 1b). Moreover, MyD88small (MyD88s) and IкB $\alpha$, both negatively regulating $\mathrm{NF}-\mathrm{\kappa} B$ activation [26], were upregulated already $4 \mathrm{~h}$ after injury. In contrast, two other negative regulators of the NF- $\mathrm{KB}$ pathway, $\mathrm{A} 20$ and SIGIRR, were not induced. Suppressor of cytokine signaling 1 (SOCS1) was only weakly induced after axotomy at these early time points (Figure $1 \mathrm{~b}$ ). Functions of the immune mediators and negative regulators are shown in Table 2.

While many reports already described the induction of cytokines and chemokines in WD, it is less obvious what type of immune response is triggered by injury in the PNS. Therefore, we decided to focus on gene expression profiles for genes associated with M1 vs. M2 macrophages, representative for the two extremes of a merely pro-inflammatory $v s$. a merely anti-inflammatory/wound healing phenotype $[25,36,37]$. The main functions of these genes are described in Table 3. We first determined when macrophages start to accumulate in our model, by analyzing the presence of three universal markers for macrophages (Iba1, CD11b, and F4/80) using RT-qPCR $[38,39]$. In general, it is considered that a first contribution to the immune response in the nerve is

Table 3 Overview of the main functions of M1 and M2 associated markers

\begin{tabular}{|c|c|c|}
\hline \multicolumn{3}{|c|}{ General macrophage markers } \\
\hline CD11b & Cluster of differentiation $11 \mathrm{~b}$ & Expressed on all myeloid lineage cells \\
\hline F4/80 (EMR1) & EGF-like module-containing mucin-like hormone receptor-like 1 & Expressed on most tissue macrophages \\
\hline lba1 & lonized calcium binding adaptor molecule 1 & Expressed on macrophages (and microglia) \\
\hline \multicolumn{3}{|c|}{ M1 associated markers } \\
\hline IFNY & Interferon gamma & $\begin{array}{l}\text { Polarize macrophages towards } \mathrm{M} 1 \text {; critical for innate } \\
\text { and adaptive immunity against viral and intracellular } \\
\text { bacterial infections (also produced by macrophages) [40] }\end{array}$ \\
\hline IL-12p40 & Interleukin 12 subunit $\mathrm{p} 40$ & $\begin{array}{l}\text { Pro-inflammatory cytokine; induces Th1[41], production } \\
\text { of cytokines (mainly IFNy) [42], stimulation cell-mediated } \\
\text { immunity against microbial pathogens [43] }\end{array}$ \\
\hline iNOS & Inducible nitric oxide synthase & $\begin{array}{l}\text { Production of nitric oxide (NO) using arginine as a substrate; } \\
\text { defense against microorganisms [44] }\end{array}$ \\
\hline \multicolumn{3}{|c|}{ M2 associated markers } \\
\hline Arg1 & Arginase 1 & $\begin{array}{l}\text { Production of L-ornithine and urea using arginine as a substrate, } \\
\text { first step to production of polyamines (growth factors in the } \\
\text { nervous system) [45]; counteracts iNOS }\end{array}$ \\
\hline$\overline{\mathrm{CDH} 1}$ & Cadherin-1 & $\begin{array}{l}\text { Cell-cell adhesion [46], interaction with CD103 of regulatory } \\
\text { T-cells [47] }\end{array}$ \\
\hline$\overline{C l e c 7 a}($ dectin1) & C-type lectin domain family 7 , member a & Pattern recognition; non-opsonic beta-glucan receptor [48] \\
\hline$\overline{\mathrm{FIZZ1}}$ & Found in inflammatory zone & Lipid and sugar metabolism; angiogenesis-promoting factor [49] \\
\hline$\overline{I L-4}$ & Interleukin 4 & $\begin{array}{l}\text { Th2 effector cytokine: polarize macrophages to M2 [50]; IgE class } \\
\text { switching, differentiation of CD4+ T-cells into Th2 cells [51] }\end{array}$ \\
\hline $\mathrm{IL}-10$ & Interleukin 10 & Anti-inflammatory cytokine [52] \\
\hline $\mathrm{IL}-13$ & Interleukin 13 & $\begin{array}{l}\text { Th2 effector cytokine: polarize macrophages to M2; fibrosis; defense } \\
\text { against parasite infections [53] }\end{array}$ \\
\hline$\overline{\mathrm{MRC1}}$ & Mannose receptor type $\mathrm{C} 1$ & Pattern recognition, type II response promoting effect [54] \\
\hline Rage & Receptor for advanced glycosylation end products & $\begin{array}{l}\text { Pattern recognition; binds endogenous ligands such as S100B to } \\
\text { stimulate trophic effects on neurons [55] }\end{array}$ \\
\hline Trem2 & Triggering receptor expressed on myeloid cells 2 & $\begin{array}{l}\text { Pattern recognition [56]; augmentation of apoptotic neuron } \\
\text { phagocytosis and attenuation of proinflammatory cytokine } \\
\text { secretion [57] }\end{array}$ \\
\hline $\mathrm{Ym} 1(\mathrm{CH} 3 \mathrm{~L} 3)$ & Chitinase 3-like-3 & $\begin{array}{l}\text { Weak eosinophils chemoattractant properties [58]; binds heparan } \\
\text { sulfate, heparin, GlcN olimers; Th2 promoting effect [59] }\end{array}$ \\
\hline
\end{tabular}




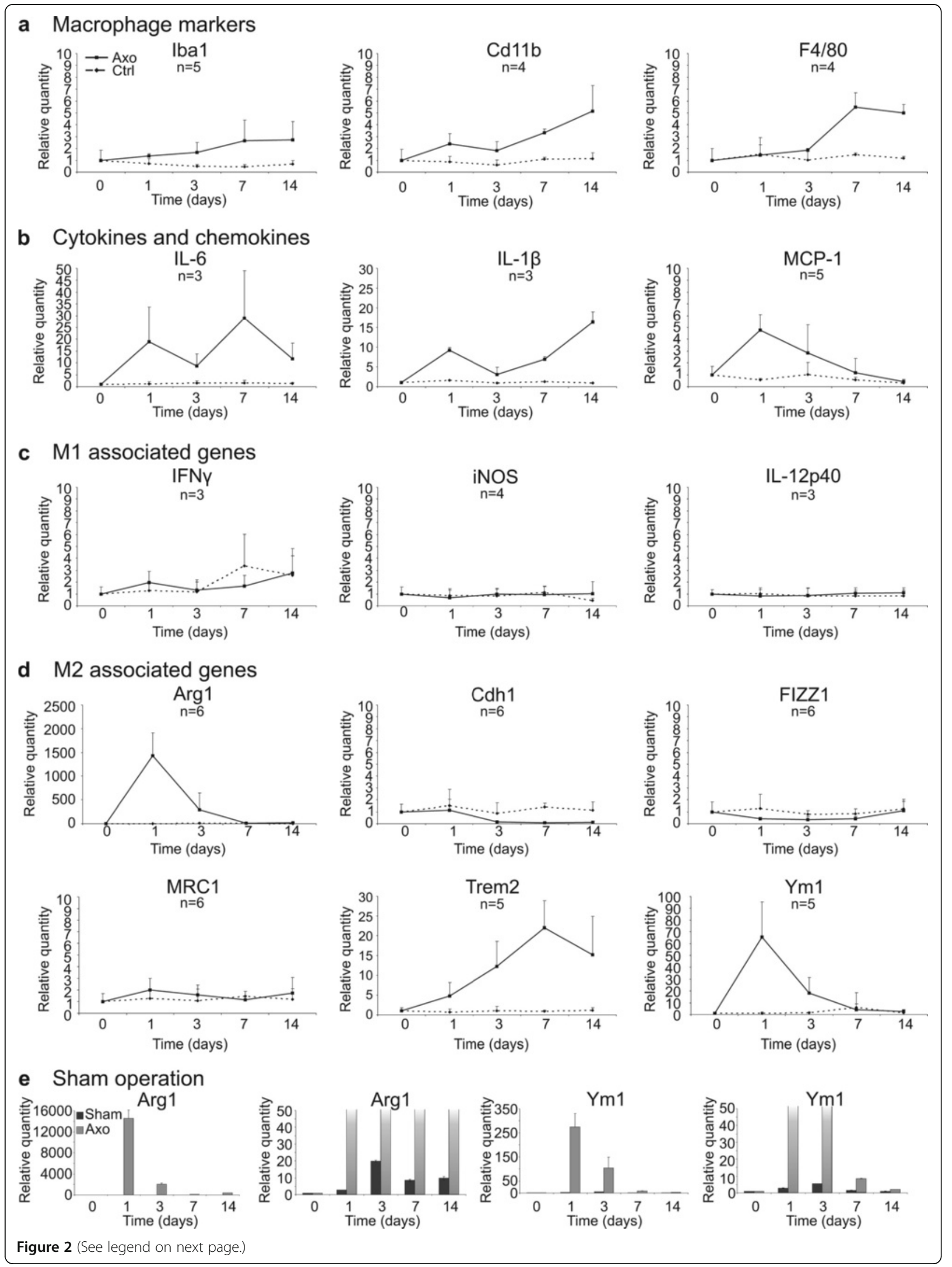


mediated by resident cells (such as Schwann cells, resident macrophages, and fibroblasts) because blood-borne monocytes infiltrate the nerve only 2 to 3 days after injury [12]. Macrophages, expressing Iba1, CD11b, and F4/ 80 , start to accumulate in the injured nerves from day 3 onwards as determined by RT-qPCR (Figure 2a) and immunohistochemistry (Figure 3). Coinciding with the accumulation of macrophages, a second peak in the immune response could be observed, as shown by the biphasic induction of IL- 6 and IL-1 $\beta$ expression (Figure 2b). As expected, MCP-1, a chemoattractant for macrophages produced by Schwann cells, is expressed right before macrophage accumulation (Figure 2b). In order to determine the phenotype of the macrophages present in the peripheral nerve after injury, we analyzed markers typically associated with M1 vs. M2 macrophages. None of the M1 markers such as iNOS, IL$12 \mathrm{p} 40$, and IFN $\gamma$ were induced after axotomy at any time point investigated (Figure 2c). On the other hand, the M2-associated genes, arginase-1 and $\mathrm{Ym1}$, were clearly induced. The expression of these genes reached a maximum at 1 day after axotomy and returned to basal level at day 7. Another typical marker for M2 macrophages, Trem2, was induced from day 3 onwards and its expression level remained elevated till day 14 after axotomy (the latest time point investigated in this study) (Figure 2d). The expression of Trem2 appeared to be mediated by the accumulating macrophages, as its expression level displayed a similar pattern as the general macrophage markers (Figure $2 \mathrm{~b}$ and $\mathrm{d}$ ). Some markers (arginase-1 and Ym1) were also slightly induced in sham-operated animals, however this induction was only minor compared to the induction seen after axotomy (Figure 2e). Altogether, these data suggest that acute peripheral nerve injury favors an M2 macrophage environment. Additional analyses confirmed this hypothesis. We found that receptors known to trigger M2 cells (such as IL-4R $\alpha$ and IL-13R $\alpha 1$ ), and to stimulate macrophage suppressor function (such as IL-10R), were induced in injured peripheral nerves at 7 and 14 days after injury (Figure 4a). The IFNYR1 receptor, which characterizes M1 macrophages, was not enhanced (Figure $4 \mathrm{~b}$ ). Moreover, scavenger receptors (such as Clec7a and Rage), which are typically expressed by M2 macrophages, showed an increased expression level after axotomy at the late time points relative to the uninjured control nerve (Figure 4c).
The M2 gene expression profile is typically triggered by the cytokines IL-4 and/or IL-13 [60]. In order to determine if these cytokines play a role in the induction of the alternative macrophage environment after axotomy, their expression level was investigated at early time points using RT-qPCR. The IL-4 expression was hardly detectable at the mRNA level in our model of acute peripheral nerve injury and did not seem to be induced. The IL-13 expression, however, was induced upon axotomy at the earliest time point $(4 \mathrm{~h})$ investigated (Figure 4d). Importantly, also the anti-inflammatory cytokine IL-10 was induced after injury (Figure $4 \mathrm{~d}$ ). The high IL-10 and low IL-12p40 expression levels are representative of a typical M2 activation profile (Figures 2c and $4 \mathrm{~d})$.

Next we analyzed the macrophage phenotype at protein level by using western blot and immunohistochemistry. As the balance between arginase-1 and iNOS expression is highly indicative of the macrophage phenotype, these two markers were used in the following experiments [36]. Western blot analysis of protein lysates of the distal segment of the sciatic nerve showed an induction of arginase-1 protein after axotomy. Arginase- 1 protein was detectable from day 1 after injury and reached a maximal signal at day 3 . Albeit showing a small decrease over time, the arginase- 1 protein level remained high until day 14 after axotomy (Figure 5a). iNOS was not detectable at any time point by western blot analysis, confirming our RT-qPCR data (Figure 5b). As a positive control, peritoneal macrophages were stimulated in vitro with either IL-4/IL-13 or LPS/IFN $\gamma$ to obtain M2 and M1 macrophages, respectively. As expected, the M2 macrophages expressed arginase-1 and the M1 macrophages expressed iNOS protein (Figure 5a, b). Immunohistochemistry of paraffin-embedded sciatic nerves confirmed the temporal expression profile for arginase- 1 shown by western blot. Arginase-1 is rapidly expressed throughout the entire injured nerve. The expression level peaked at 3 days post injury and remained high until day 14 (Figure 5c). Double immunofluorescence staining revealed that arginase- 1 was present in F4/80 positive cells and not in S100 positive Schwann cells, which identifies macrophages as the main source for arginase-1 (Figure 6). While at earlier time points all cells that expressed F4/ 80 were found to be positive for arginase-1, at later time points arginase- 1 negative macrophages were present as 


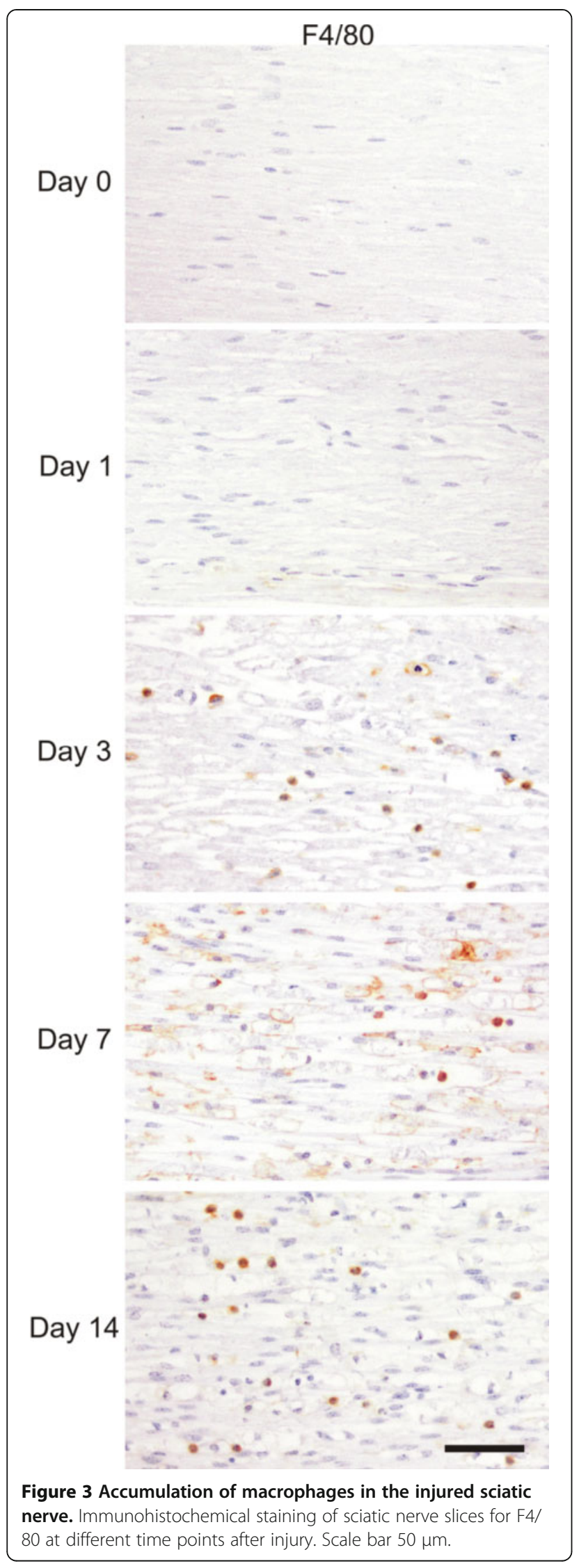

well. Immunohistochemical staining for iNOS confirmed that this protein was not induced after axotomy (Figure $5 \mathrm{c}$ ). We only observed strong iNOS staining in blood capillaries in particular regions on the nerve that was present independently of the axotomy, showing that the antibody staining was working properly (Figure $5 \mathrm{~d}$ ).

Finally, we determined whether the M2-predominated immune response triggered after nerve injury is typical for the PNS or whether it is specific for neurodegeneration. To this end, we investigated at different time points the expression of M1 and M2 markers in sciatic nerves from mice intravenously injected with TLR-ligands. We used lipopolysaccharide (LPS), a TLR4 ligand known to induce a classical type I immune response, and Pam3Cys, a TLR1/2 ligand. Intravenous injection of LPS as well as Pam3Cys elicited a rapid and strong immune response in the sciatic nerve, as shown by the induction of inflammatory genes such as IL- $1 \beta$, Cox 2 , MIP- $1 \alpha$, and MCP-1 (Figure 7a). Interestingly, the pro-inflammatory cytokine IL-12p40 and typical M1 immune mediator iNOS, both representative for a type I immune response, were induced after LPS injection (Figure 7b). Several negative regulators, such as IL-1RA, MyD88s, and SOCS1, which mediate a negative feedback loop, were also induced by LPS injection (Figure 7c). Injection with Pam3Cys, however, clearly induced a mixed immune response as reflected by the expression of the M1 associated cytokine IL-12p40 and the expression of Ym1, which is an M2-associated macrophage marker (Figure 7b). iNOS was not detectable after Pam3Cys injection (Figure 7b) and none of the other M2associated genes such as arginase- 1 and Trem2 were induced (Figure $7 \mathrm{~b}$ ). These data show that a prototypical type I immune response can be observed in the nerve after injection of LPS, while Pam3Cys seems to induce a mixed immune response. Both TLR-mediated responses clearly differed from the immune response induced after acute peripheral nerve injury.

\section{Discussion}

In response to an infection, a strong pro-inflammatory immune response is triggered. The recruited inflammatory cells are activated when they encounter pathogenassociated molecular products (PAMPs) such as LPS. Hereupon, these cells phagocytose infectious agents and produce pro-inflammatory mediators such as iNOS, IL12 , ROS, and RNS to fight off the invading pathogen. These agents, however, can also cause tissue damage. The innate immune system also detects the presence of endogenous molecules; so-called danger associated molecular patterns (DAMPs) that are only exposed in conditions of injury. Under conditions of cellular stress or injury, one might expect a more dampened, strictly controlled immune response as the cost-benefit ratio is higher. As we and others have shown, pro-inflammatory 


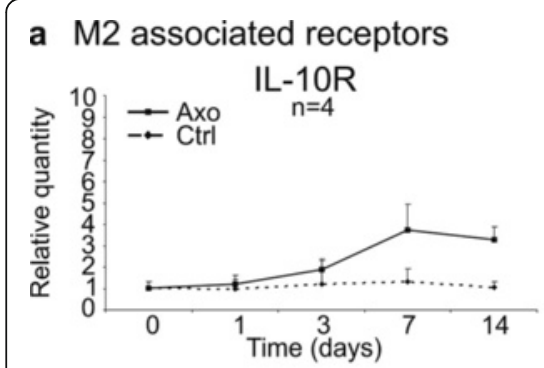

b M1 associated receptor
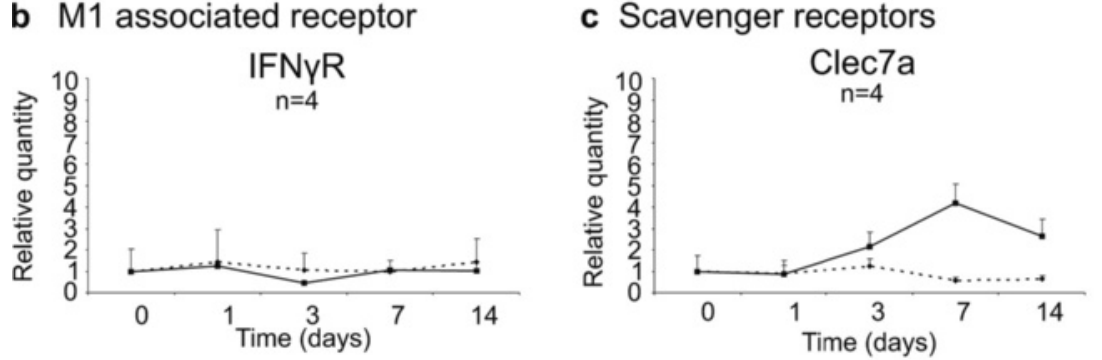

d M2 inducing and anti-inflammatory cytokines
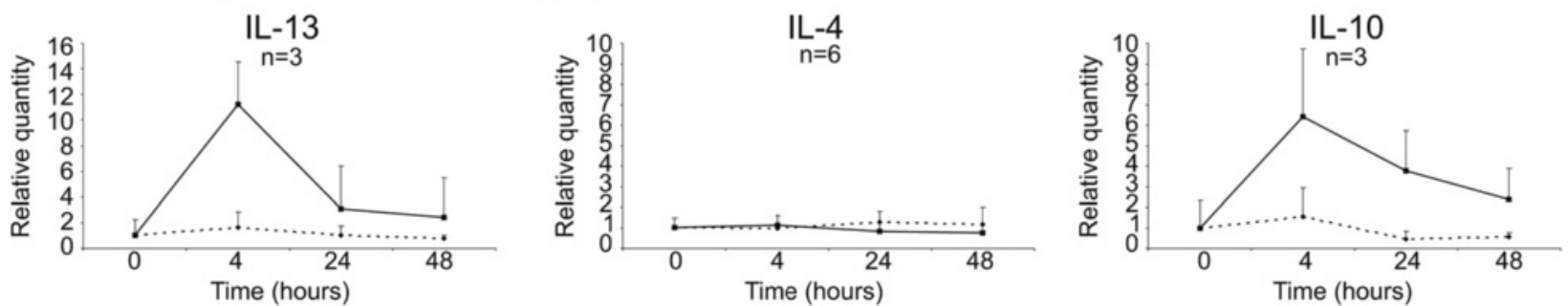

Figure 4 Peripheral nerve injury is associated with the expression of $M 2$-associated cytokines and cytokine receptors. RT-qPCR analysis of the sciatic nerve showing cytokine receptor expression profiles upon injury (a, b), scavenger receptor expression (c), and expression of M2 cytokines (d). The mRNA levels are expressed relative to the basal condition ( $=0 \mathrm{~h}$ time point). Data presented are the compiled data of different independent experiments, with $\mathrm{n}$ representing the number of independent experiments for each gene.

mediators such as IL- $1 \beta$ and Cox 2 and chemokines such as MIP- $1 \alpha$ and MCP-1 are rapidly induced in WD, a model of sterile inflammation in the nerve $[3,4]$. In the present study we show that the expression of these inflammatory genes is strictly controlled as the mRNA levels of all cytokines and chemokines return to basal level at 48 h. Negative regulators of the proinflammatory signaling pathways are induced prior to the decline in inflammatory gene expression, thereby limiting the pro-inflammatory immune response and also the excessive damage caused by the immune system.

Although PAMPs and DAMPs are recognized by the same set of receptors, such as TLRs, they can induce a different set of genes [61]. Bacterial compounds trigger a microbicidal environment and classically activated M1 macrophages; while endogenous molecules seem to activate an inflammatory response associated with genes that mediate tissue repair [61,62]. Since most studies so far focused specifically on the induction of proinflammatory mediators, WD in the PNS has always been associated with the induction of a strong proinflammatory immune response. We found, however, by analyzing genes associated with M1 and M2 macrophages, that acute peripheral nerve injury rather induces an M2-like macrophage environment. None of the typical pro-inflammatory markers of the M1 subtype of macrophages such as iNOS, IFN $\gamma$, and IL12p40 could be detected, while M2 markers such as arginase-1, Ym1, and Trem2 were highly up-regulated. Intriguingly, other M2 markers like Fizz1 and Cdh1 were not induced. Van den Bossche et al. showed that some M2 markers like Cdh1 are strongly downregulated by the presence of pro-inflammatory cytokines [63]. This could be the case here as well. The stimulation of the alternative macrophage environment in the nerve appeared to be controlled at the level of IL-13. This cytokine was readily detectable from $4 \mathrm{~h}$ after the onset of neurodegeneration, and prior to the expression of arginase-1 and Ym1. IL-13, which is together with IL-4 a central master switch in the M2 phenotype, is typically expressed by macrophages, basophils, mast cells, or activated T cells [64]. Since we detect accumulation of macrophages only from days 2 to 3 onwards, it is less clear at the moment which cells 


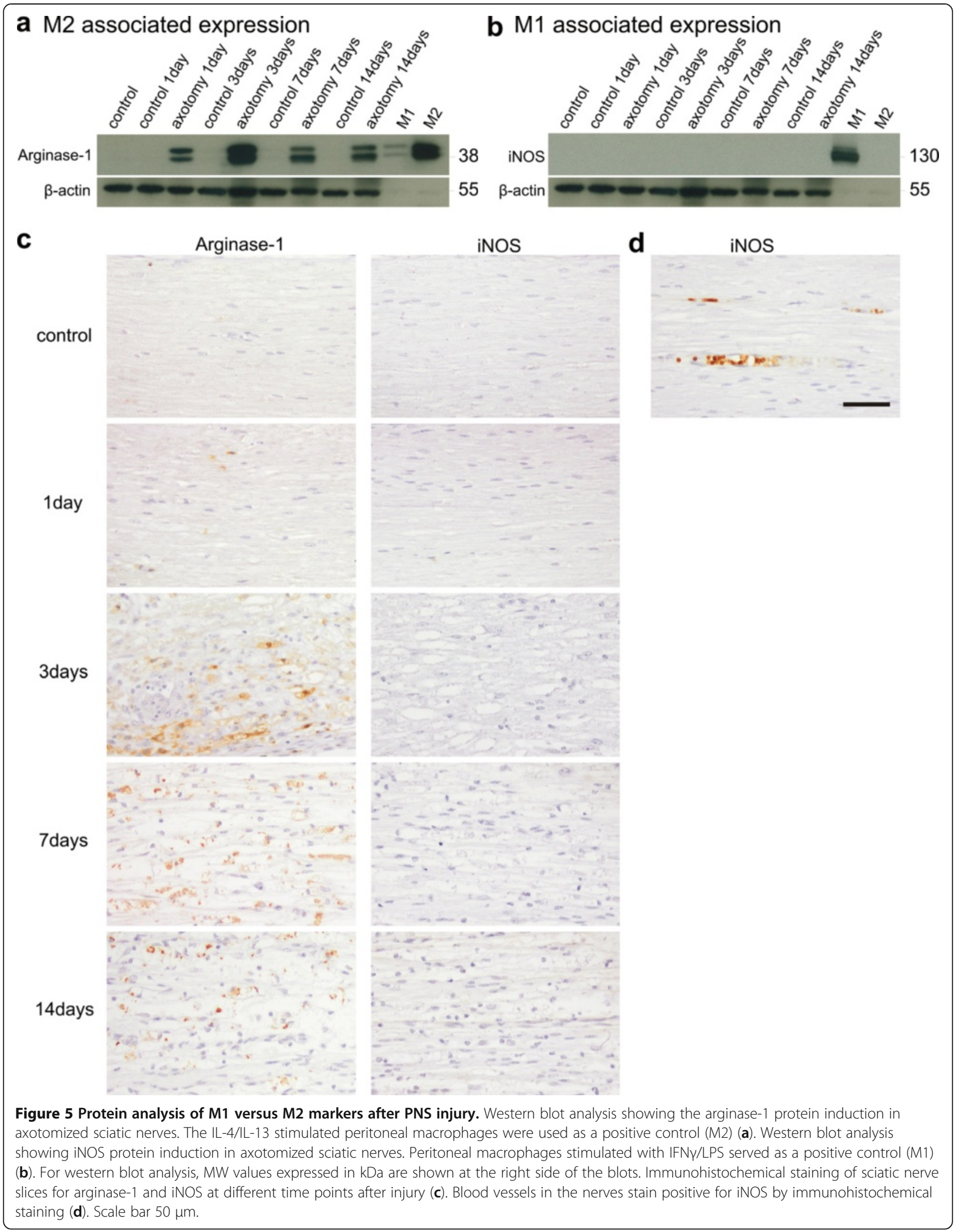




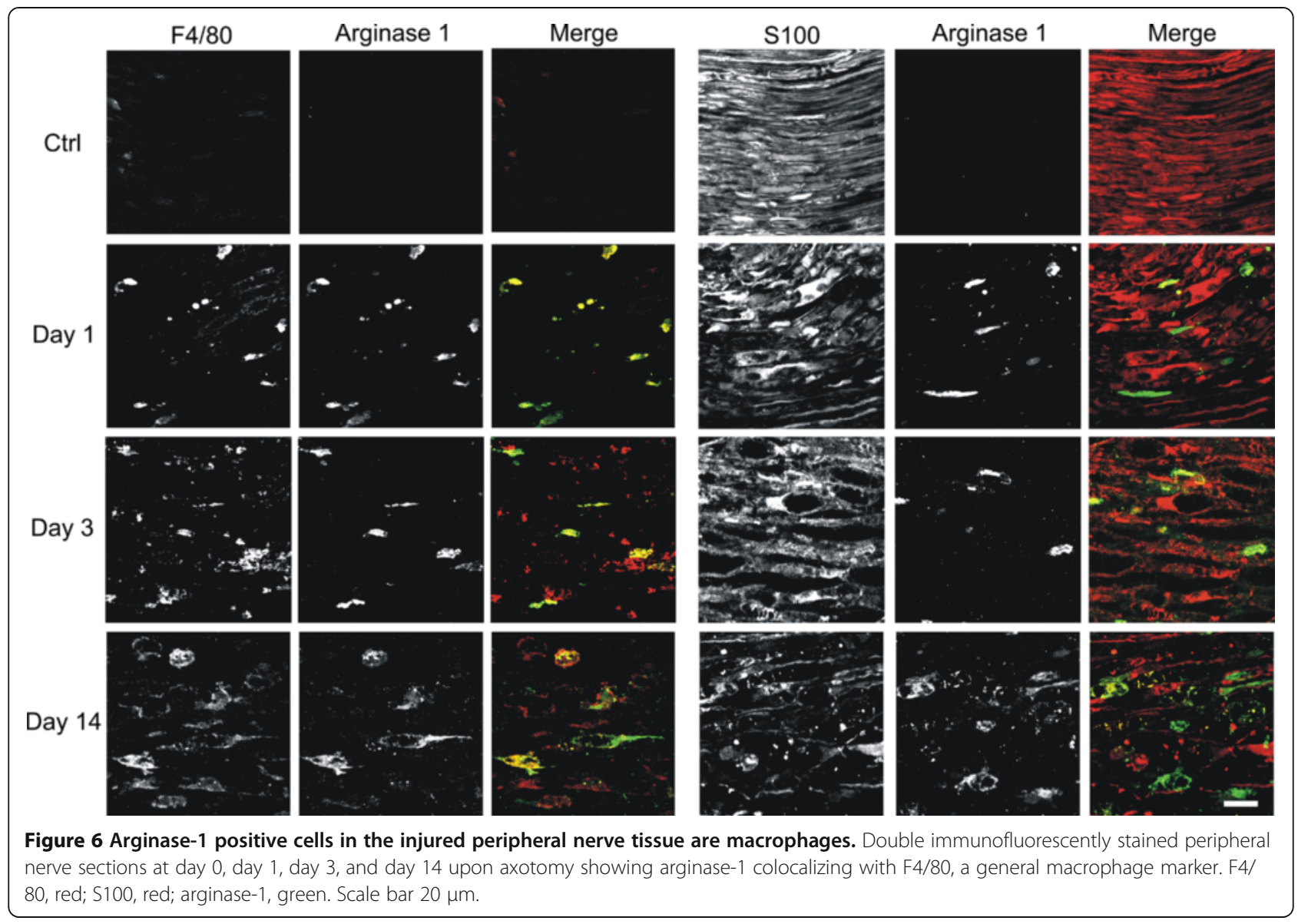

are responsible for the early onset expression of IL-13, arginase-1, or Ym1. In the peripheral nerve resident macrophages, mast cells or SCs could be engaged in the expression of IL-13, while neutrophils could contribute to the expression of arginase-1 and Ym1. Neutrophils are recruited to the damaged nerves at day 1 after injury [65], and are suggested to contribute to the expression of tissue repair genes [66]. Our results demonstrate that damage to the nerve establishes a rapid immunosuppressive reaction within the nerve, and this from very early time points on, which appears to be in contrast with another recent report [67]. Shechter et al. described that axotomy of the optic nerve creates a pro-inflammatory environment in the nerve that was later turned into an anti-inflammatory one by infiltrating macrophages [67]. Macrophages have been shown before to play a beneficial role in WD in the PNS, as depleting them impaired functional recovery [68]. By phagocytosing debris, macrophages contribute to regeneration by removing inhibitory myelin debris and paving the way for neurite outgrowth. Pre-existing autoantibodies have been shown to play an important role in clearance of myelin debris by promoting a macrophage influx and stimulating their phagocytic activity
[69]. In addition, macrophages produce neurotrophic factors, thereby supporting regeneration [70]. The protective role of macrophages in WD might also be explained by their phenotype. The M2 macrophages were shown to be neuroprotective in vitro by stimulating neurite outgrowth, while M1 macrophages were neurotoxic to neuronal cell cultures [71]. Moreover, potent inducers of a systemic Th2 switch, such as glatiramer acetate and statins, support the neuroprotection and/or nerve regeneration [72-74]. The Th2-inducing adjuvants, such as IFA and Alum, promote axon regeneration better than the Th1-inducing adjuvant CFA $[75,76]$. Also Th2 cells support neuronal survival in vitro to a greater extent than Th1 cells [77].

In autoimmune diseases of the PNS such as GuillianBarré Syndrome (GBS) and chronic inflammatory demyelinating polyneuropathy (CIDP), a Th1 response is associated with the early stages of the disease. During recovery of GBS and CIDP, a shift towards a Th2 response is observed, suggesting a protective role for Th2 responses in these diseases [78-80]. Also from animal models it is apparent that type II immune responses are beneficial; as nasal administration of recombinant IL-4 ameliorates ongoing experimental autoimmune neuritis 


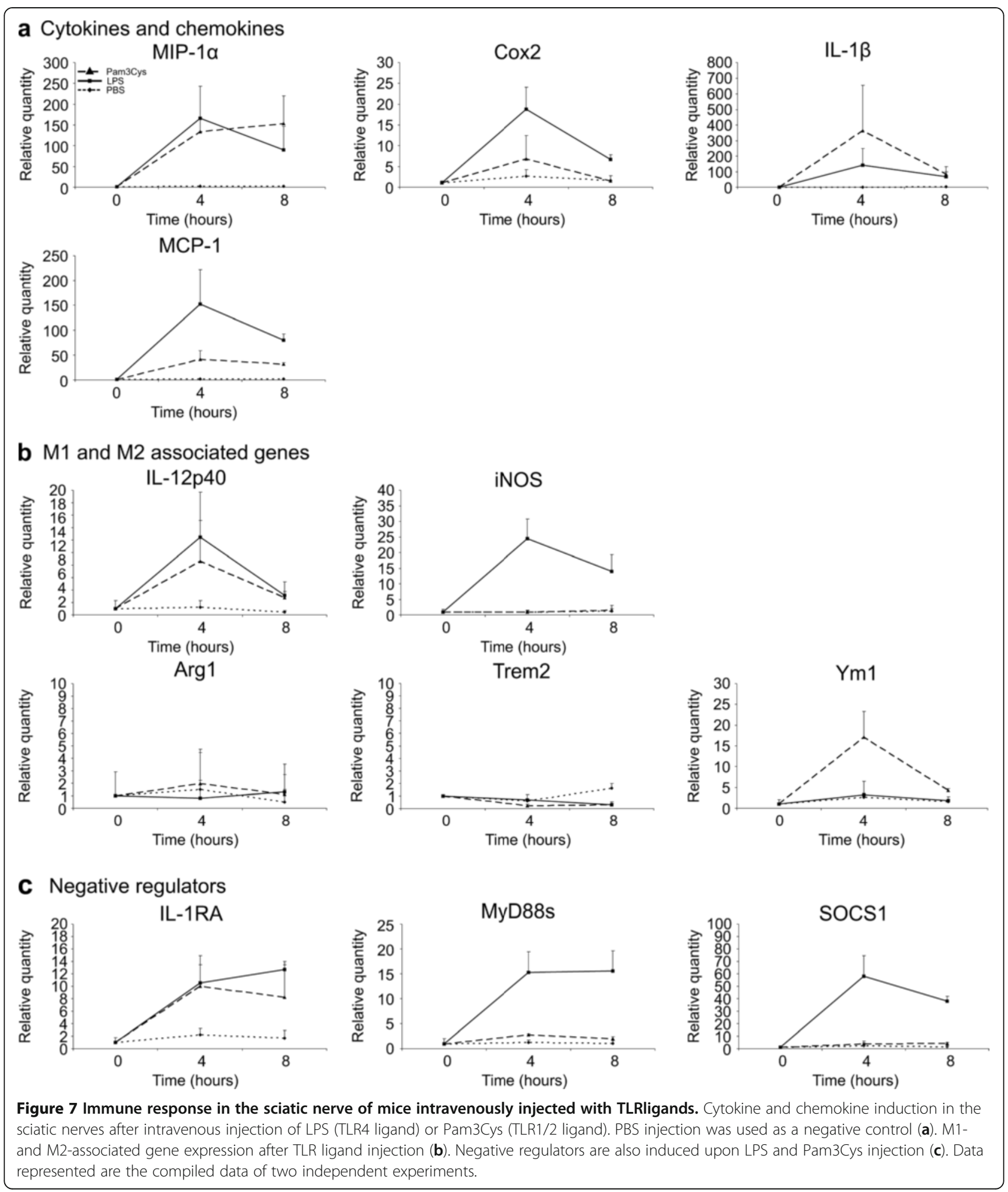

(EAN) and inhibits demyelination [81]. The self-limiting clinical course of GBS might be explained by the induction of IL-4 and IL-10. The role of the immune system in hereditary neuropathies is less well studied. Patients suffering from inherited neuropathies show endoneurial $\mathrm{T}$ - cells in their nerve biopsies and some patients even show inflammatory infiltrates $[82,83]$. Studies with animal models such as the heterozygote P0 mice, a model of Charcot-Marie-Tooth (CMT) 1B neuropathy, clearly show a functional degenerative role for macrophages and 
T-cells $[84,85]$. Unfortunately, the type of immune response triggered in hereditary neuropathies has not been addressed.

In CNS injury, macrophages have been implicated in both exacerbating as well as ameliorating tissue damage at the injury site. Kigerl et al. showed that spinal cord injury (SCI) initially induces both M1 and M2 macrophages, however, the M1 phenotype predominates the lesion site after 1 week [71]. The presence of both phenotypes might explain the dual effect of macrophages in this model. Moreover, axonal regeneration after SCI is prevented by an inhibitory environment due to myelin inhibitors. Qui et al. showed that elevating cAMP was sufficient to overcome the myelin-mediated inhibition [86]. Subsequent studies showed that arginase- 1 and polyamines played a major protective role downstream of cAMP [45]. By using PNS grafts together with acidic fibroblast growth factor in a model of SCI, the recruited macrophages produced large amounts of arginase- 1 and were involved in polyamine synthesis [87]. This strategy significantly improved functional recovery [88]. Altogether these data show a central role for type II immune responses, arginase-1 and downstream polyamines in regeneration.

Lessons from graft implantation in CNS injury showed that PNS tissue induces a permissive environment for regeneration. Macrophages contribute to this permissive environment as spinal cord-injured axons failed to regenerate through peripheral nerve grafts in the absence of $\mathrm{CD}_{11 b^{+}}$cells [68]. We now hypothesize that PNS injury triggers an inherent protective environment by inducing an M2 phenotype of macrophages and arginase-1 expression. This model can further be used to unravel how the environment is induced and to elucidate which protective program needs to be elicited. Currently, it remains to be shown how the alternative macrophage environment is established; however there might be a role for IL-13, a typical M2 inducer, as this cytokine is up-regulated very early after injury and prior to the M2associated gene expression.

Finally, the induction of the alternative macrophage environment appeared to be triggered specifically in response to neurodegeneration. Our results show that when challenged with bacterial products such as LPS, a typical pro-inflammatory immune response, as reflected by a strong IL-12p40 and iNOS signal and the absence of $\mathrm{Ym} 1$ or arginase-1, could be detected within the PNS. Intriguingly, injection with Pam3Cys, a TLR1/2 ligand, induced a mixed response marked by presence of both IL-12p40 and Ym1 induction. TLR2, the co-receptor for TLR1, has been associated before with the induction of a type II gene expression $[89,90]$. In a recent study we showed that specifically TLR1 was highly induced after acute peripheral nerve injury and hypothesized that it might play a role in detecting neuronal injury [22]. The possible involvement of TLR $1 / 2$ in the detection of peripheral nerve injury and in the switch towards the type II gene expression is currently under investigation.

\section{Conclusion}

In conclusion, we demonstrate that acute peripheral nerve injury induces an inherent protective response with the initiation of several negative feedback loops, limiting excessive tissue damage. Furthermore, we show that an M2-like anti-inflammatory environment is induced, rather than a pro-inflammatory one. Since type II responses have been shown before to be neuroprotective, we believe that instead of inhibiting the immune responses, shifting the macrophage phenotype or type of immune response towards an alternative activation state or type II response would be a better therapeutic strategy to stimulate repair, as this would create a permissive environment for neuronal regeneration.

\section{Abbreviations}

CFA: Complete freund's adjuvant; CIDP: Chronic inflammatory demyelinating polyneuropathy; CMT: Charcot-Marie-Tooth; CNS: Central nervous system; DAB: 3,3'-Diaminobenzidine; DAMP: Danger associated molecular pattern; EAN: Experimental autoimmune neuritis; GBS: Guillian-Barré Syndrome; IFA: Incomplete freund's adjuvant; LPS: Lipopolysaccharide; MyD88s: Myeloid differention 88 small; PAMP: Pathogen associated molecular pattern; PNS: Peripheral nervous system; RNS: Reactive nitric species; ROS: Reactive oxygen species; RT-qPCR: Real-time quantitative polymerase chain reaction; SC: Schwann cell; SCI: Spinal cord injury; SOCS1: Suppressor of cytokine signaling 1; WD: Wallerian degeneration.

\section{Competing interests}

The authors declare that they have no competing interests.

\section{Acknowledgements}

The study was supported by the University of Antwerp and the Fund for Scientific research (FWO-Flanders). EY is supported by an IWT doctoral fellowship. We would like to thank Dr Chantal Ceuterick-De Grootte and members of the Institute Born-Bunge for their help with histological sections and Dr Delphine Bouhy and all members of the Peripheral Neuropathy group for helpful discussions.

\section{Author details}

${ }^{1}$ Peripheral Neuropathy Group, Department of Molecular Genetics, VIB and University of Antwerp, Antwerpen, Belgium. 2Department of Biomedical Molecular Biology, Ghent University, Ghent, Belgium. ${ }^{3}$ Department for Molecular Biomedical Research, VIB, Ghent, Belgium. ${ }^{4}$ GROUP-ID Consortium, Laboratory for Immunoregulation and Mucosal Immunology,

GhentUniversity, Ghent, Belgium. ${ }^{5}$ Laboratory of Cellular and Molecular Immunology, Vrije Universiteit Brussel, Brussels, Belgium. ${ }^{6}$ Myeloid Cell Immunology Lab, VIB, Brussels, Belgium.

\section{Authors' contributions}

EY carried out the experiments and wrote the manuscript, together with SJ. AC preformed the intravenous injections. BA provided expertise on microscopy. SG, LP, and GL assisted in the animal surgery and experiments. LAS and JAVG contributed to the interpretation of the results and discussed analyses. VT and SJ designed the methods and experiments. All the authors read and approve the final version of the manuscript.

Received: 15 March 2012 Accepted: 20 July 2012

Published: 20 July 2012

\section{References}

1. Waller A: Experiments on the section of the glossopharyngeal and hypoglossal nerves of the frog, and observations of the alterations 
produced thereby in the structure of their primitive fibres. Phil Transact Royal Soc London 1850, 140:423-429.

2. Saxena S, Caroni P: Mechanisms of axon degeneration: from development to disease. Prog Neurobio/ 2007, 83:174-191.

3. Shamash S, Reichert F, Rotshenker S: The cytokine network of Wallerian degeneration: tumor necrosis factor-alpha, interleukin-1alpha, and interleukin-1 beta. J Neurosci 2002, 22:3052-3060

4. Perrin FE, Lacroix S, Aviles-Trigueros M, David S: Involvement of monocyte chemoattractant protein-1, macrophage inflammatory protein-1alpha and interleukin-1beta in Wallerian degeneration. Brain 2005, 128:854-866.

5. Taskinen HS, Olsson T, Bucht A, Khademi M, Svelander L, Roytta M: Peripheral nerve injury induces endoneurial expression of IFN-gamma, IL-10 and TNF-alpha mRNA. J Neuroimmunol 2000, 102:17-25.

6. Subang MC, Richardson PM: Influence of injury and cytokines on synthesis of monocyte chemoattractant protein-1 mRNA in peripheral nervous tissue. Eur J Neurosci 2001, 13:521-528.

7. Taskinen HS, Roytta M: Increased expression of chemokines (MCP-1, MIP1alpha, RANTES) after peripheral nerve transection. J Peripher Nerv Syst 2000, 5:75-81

8. Toews AD, Barrett C, Morell P: Monocyte chemoattractant protein 1 is responsible for macrophage recruitment following injury to sciatic nerve. J Neurosci Res 1998, 53:260-267.

9. Zuo Y, Perkins NM, Tracey DJ, Geczy CL: Inflammation and hyperalgesia induced by nerve injury in the rat: a key role of mast cells. Pain 2003, 105:467-479.

10. Moalem G, Tracey DJ: Immune and inflammatory mechanisms in neuropathic pain. Brain Res Rev 2006, 51:240-264.

11. Bendszus M, Stoll G: Caught in the act: in vivo mapping of macrophage infiltration in nerve injury by magnetic resonance imaging. J Neurosci 2003, 23:10892-10896

12. Mueller M, Leonhard C, Wacker K, Ringelstein EB, Okabe M, Hickey WF, Kiefer R: Macrophage response to peripheral nerve injury: the quantitative contribution of resident and hematogenous macrophages. Lab Invest 2003, 83:175-185.

13. Taskinen HS, Roytta M: The dynamics of macrophage recruitment after nerve transection. Acta Neuropathol 1997, 93:252-259.

14. Perry VH, Brown MC, Gordon S: The macrophage response to central and peripheral nerve injury. A possible role for macrophages in regeneration. J Exp Med 1987, 165:1218-1223.

15. Mueller M, Wacker K, Ringelstein EB, Hickey WF, Imai Y, Kiefer R: Rapid response of identified resident endoneurial macrophages to nerve injury. Am J Pathol 2001, 159:2187-2197.

16. Hirata K, Kawabuchi M: Myelin phagocytosis by macrophages and nonmacrophages during Wallerian degeneration. Microsc Res Tech 2002, 57:541-547.

17. Omura T, Omura K, Sano M, Sawada T, Hasegawa T, Nagano A: Spatiotemporal quantification of recruit and resident macrophages after crush nerve injury utilizing immunohistochemistry. Brain Res 2005 1057:29-36

18. Sawada T, Sano M, Omura T, Omura K, Hasegawa T, Funahashi S, Nagano A: Spatiotemporal quantification of tumor necrosis factor-alpha and interleukin-10 after crush injury in rat sciatic nerve utilizing immunohistochemistry. Neurosci Lett 2007, 417:55-60.

19. Liefner $M$, Siebert $H$, Sachse $T$, Michel $U$, Kollias G, Bruck W: The role of TNF-alpha during Wallerian degeneration. J Neuroimmunol 2000, 108:147-152.

20. Gillen C, Jander S, Stoll G: Sequential expression of mRNA for proinflammatory cytokines and interleukin-10 in the rat peripheral nervous system: comparison between immune-mediated demyelination and Wallerian degeneration. J Neurosci Res 1998, 51:489-496.

21. de la $\mathrm{Hoz} C L$, Oliveira AL, Queiroz Lde S, Langone F: Wallerian degeneration in C57BL/6J and A/J mice: differences in time course of neurofilament and myelin breakdown, macrophage recruitment and iNOS expression. J Anat 2003, 203:567-578.

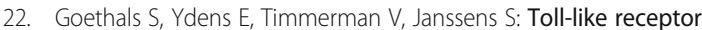
expression in the peripheral nerve. Glia 2010, 58:1701-1709.

23. Vandesompele J, De Preter K, Pattyn F, Poppe B, Van Roy N, De Paepe A Speleman F: Accurate normalization of real-time quantitative RT-PCR data by geometric averaging of multiple internal control genes. Genome Biol 2002, 3:RESEARCH0034.
24. Hellemans J, Mortier G, De Paepe A, Speleman F, Vandesompele J: qBase relative quantification framework and software for management and automated analysis of real-time quantitative PCR data. Genome Biol 2007, 8:R19.

25. Ghassabeh GH, De Baetselier P, Brys L, Noel W, Van Ginderachter JA, Meerschaut S, Beschin A, Brombacher F, Raes G: Identification of a common gene signature for type II cytokine-associated myeloid cells elicited in vivo in different pathologic conditions. Blood 2006, 108:575-583.

26. Janssens S, Burns K, Tschopp J, Beyaert R: Regulation of interleukin-1- and lipopolysaccharide-induced NF-kappaB activation by alternative splicing of MyD88. Curr Biol 2002, 12:467-471

27. Tsou CL, Peters W, Si Y, Slaymaker S, Aslanian AM, Weisberg SP, Mack M, Charo IF: Critical roles for CCR2 and MCP-3 in monocyte mobilization from bone marrow and recruitment to inflammatory sites. J Clin Invest 2007, 117:902-909

28. Morita I: Distinct functions of COX-1 and COX-2. Prostaglandins Other Lipid Mediat 2002, 68-69:165-175.

29. Ma W, Quirion R: Does COX2-dependent PGE2 play a role in neuropathic pain? Neurosci Lett 2008, 437:165-169.

30. Dinarello CA: Immunological and inflammatory functions of the interleukin-1 family. Annu Rev Immunol 2009, 27:519-550.

31. Kishimoto T: IL-6: from its discovery to clinical applications. Int Immunol 2010, 22:347-352.

32. Boone DL, Turer EE, Lee EG, Ahmad RC, Wheeler MT, Tsui C, Hurley P, Chien M, Chai S, Hitotsumatsu O, McNally E, Pickart C, Ma A: The ubiquitinmodifying enzyme $\mathrm{A} 20$ is required for termination of Toll-like receptor responses. Nat Immunol 2004, 5:1052-1060.

33. Jacobs MD, Harrison SC: Structure of an IkappaBalpha/NF-kappaB complex. Cell 1998, 95:749-758.

34. Wald D, Qin J, Zhao Z, Qian Y, Naramura M, Tian L, Towne J, Sims JE, Stark GR, Li X: SIGIRR, a negative regulator of Toll-like receptor-interleukin 1 receptor signaling. Nat Immunol 2003, 4:920-927.

35. Yasukawa H, Misawa $H$, Sakamoto H, Masuhara M, Sasaki A, Wakioka T, Ohtsuka S, Imaizumi T, Matsuda T, Ihle JN, Yoshimura A: The JAK-binding protein JAB inhibits Janus tyrosine kinase activity through binding in the activation loop. EMBO J 1999, 18:1309-1320

36. Van Ginderachter JA, Movahedi K: Hassanzadeh Ghassabeh G, Meerschaut S, Beschin A, Raes G, De Baetselier P: Classical and alternative activation of mononuclear phagocytes: picking the best of both worlds for tumor promotion. Immunobiology 2006, 211:487-501

37. Raes G, Van den Bergh R, De Baetselier P, Ghassabeh GH, Scotton C, Locat M, Mantovani A, Sozzani S: Arginase-1 and Ym1 are markers for murine, but not human, alternatively activated myeloid cells. J Immunol 2005 , 174:6561. Author reply 6561-6562.

38. Kohler C: Allograft inflammatory factor-1/lonized calcium-binding adapter molecule 1 is specifically expressed by most subpopulations of macrophages and spermatids in testis. Cell Tissue Res 2007, 330:291-302.

39. Murray PJ, Wynn TA: Protective and pathogenic functions of macrophage subsets. Nat Rev Immunol 2011, 11:723-737.

40. Mege $J$, Mehraj $\vee$, Capo C: Macrophage polarization and bacterial infections. Curr Opin Infect Dis 2011, 24:230-234.

41. Hsieh CS, Macatonia SE, Tripp CS, Wolf SF, O'Garra A, Murphy KM: Development of TH1 CD4+ T cells through IL-12 produced by Listeriainduced macrophages. Science 1993, 260:547-549.

42. Gately MK, Renzetti LM, Magram J, Stern AS, Adorini L, Gubler U, Presky DH: The interleukin-12/interleukin-12-receptor system: role in normal and pathologic immune responses. Annu Rev Immunol 1998, 16:495-521.

43. Mattner F, Ozmen L, Podlaski FJ, Wilkinson VL, Presky DH, Gately MK, Alber $\mathrm{G}$ : Treatment with homodimeric interleukin-12 (IL-12) p40 protects mice from IL-12-dependent shock but not from tumor necrosis factor alphadependent shock. Infect Immun 1997, 65:4734-4737.

44. MacMicking J, Xie QW, Nathan C: Nitric oxide and macrophage function. Annu Rev Immunol 1997, 15:323-350.

45. Cai D, Deng K, Mellado W, Lee J, Ratan RR, Filbin MT: Arginase I and polyamines act downstream from cyclic AMP in overcoming inhibition of axonal growth MAG and myelin in vitro. Neuron 2002, 35:711-719.

46. Wheelock MJ, Jensen PJ: Regulation of keratinocyte intercellular junction organization and epidermal morphogenesis by E-cadherin. J Cell Biol 1992, 117:415-425. 
47. Suffia I, Reckling SK, Salay G, Belkaid Y: A role for CD103 in the retention of CD4+CD25+ Treg and control of Leishmania major infection. J Immunol 2005, 174:5444-5455

48. Brown GD, Taylor PR, Reid DM, Willment JA, Williams DL, Martinez-Pomares L, Wong SY, Gordon S: Dectin-1 is a major beta-glucan receptor on macrophages. J Exp Med 2002, 196:407-412.

49. Teng X, Li D, Champion HC, Johns RA: FIZZ1/RELMalpha, a novel hypoxiainduced mitogenic factor in lung with vasoconstrictive and angiogenic properties. Circ Res 2003, 92:1065-1067.

50. Martinez FO, Helming L, Gordon S: Alternative activation of macrophages: an immunologic functional perspective. Annu Rev Immunol 2009, 27:451-483.

51. Swain SL, Weinberg AD, English M, Huston G: IL-4 directs the development of Th2-like helper effectors. J Immunol 1990, 145:3796-3806.

52. Moore KW, de Waal Malefyt R, Coffman RL, O'Garra A: Interleukin-10 and the interleukin-10 receptor. Annu Rev Immunol 2001, 19:683-765.

53. Wynn TA: IL-13 effector functions. Annu Rev Immunol 2003, 21:425-456.

54. Chieppa M, Bianchi G, Doni A, Del Prete A, Sironi M, Laskarin G, Monti P, Piemonti L, Biondi A, Mantovani A, Introna M, Allavena P: Cross-linking of the mannose receptor on monocyte-derived dendritic cells activates an anti-inflammatory immunosuppressive program. J Immunol 2003, 171:4552-4560.

55. Sparvero LJ, Asafu-Adjei D, Kang R, Tang D, Amin N, Im J, Rutledge R, Lin B, Amoscato AA, Zeh HJ, Lotze MT: RAGE (Receptor for Advanced Glycation Endproducts), RAGE ligands, and their role in cancer and inflammation. J Transl Med 2009, 7:17

56. Daws MR, Sullam PM, Niemi EC, Chen TT, Tchao NK, Seaman WE: Pattern recognition by TREM-2: binding of anionic ligands. J Immunol 2003, 171:594-599.

57. Turnbull IR, Gilfillan S, Cella M, Aoshi T, Miller M, Piccio L, Hernandez M, Colonna M: Cutting edge: TREM-2 attenuates macrophage activation. J Immunol 2006, 177:3520-3524.

58. Owhashi M, Arita H, Hayai N: Identification of a novel eosinophil chemotactic cytokine (ECF-L) as a chitinase family protein. J Biol Chem 2000, 275:1279-1286.

59. Arora M, Chen L, Paglia M, Gallagher I, Allen JE, Vyas YM, Ray A, Ray P: Simvastatin promotes Th2-type responses through the induction of the chitinase family member Ym1 in dendritic cells. Proc Natl Acad Sci U S A 2006, 103:7777-7782.

60. Gordon S: Alternative activation of macrophages. Nat Rev Immunol 2003, 3:23-35.

61. Piccinini AM, Midwood KS: DAMPening inflammation by modulating TLR signalling. Mediators Inflamm 2010, 2010, pii: 672395

62. Li M, Carpio DF, Zheng Y, Bruzzo P, Singh V, Ouaaz F, Medzhitov RM, Beg $A A$ : An essential role of the NF-kappa B/Toll-like receptor pathway in induction of inflammatory and tissue-repair gene expression by necrotic cells. J Immunol 2001, 166:7128-7135.

63. Van den Bossche J, Bogaert P, van Hengel J, Guerin CJ, Berx G, Movahedi K, Van den Bergh R, Pereira-Fernandes A, Geuns JM, Pircher H, Dorny P, Grooten J, De Baetselier P, Van Ginderachter JA: Alternatively activated macrophages engage in homotypic and heterotypic interactions through IL-4 and polyamine-induced E-cadherin/catenin complexes. Blood 2009, 114:4664-4674.

64. Anthony RM, Rutitzky LI, Urban JF Jr, Stadecker MJ, Gause WC: Protective immune mechanisms in helminth infection. Nat Rev Immunol 2007, 7:975-987.

65. Nadeau S, Filali M, Zhang J, Kerr BJ, Rivest S, Soulet D, Iwakura Y, de Rivero Vaccari JP, Keane RW, Lacroix S: Functional recovery after peripheral nerve injury is dependent on the pro-inflammatory cytokines IL-1beta and TNF: implications for neuropathic pain. J Neurosci 2011, 31:12533-12542.

66. Loke P, Gallagher I, Nair MG, Zang X, Brombacher F, Mohrs M, Allison JP, Allen JE: Alternative activation is an innate response to injury that requires CD4+ T cells to be sustained during chronic infection. J Immunol 2007, 179:3926-3936.

67. Shechter R, London A, Varol C, Raposo C, Cusimano M, Yovel G, Rolls A, Mack M, Pluchino S, Martino G, Jung S, Schwartz M: Infiltrating bloodderived macrophages are vital cells playing an anti-inflammatory role in recovery from spinal cord injury in mice. PLoS Med 2009, 6:e1000113.

68. Barrette B, Hebert MA, Filali M, Lafortune K, Vallieres N, Gowing G, Julien JP, Lacroix S: Requirement of myeloid cells for axon regeneration. J Neurosci 2008, 28:9363-9376.
69. Vargas ME, Watanabe J, Singh SJ, Robinson WH, Barres BA: Endogenous antibodies promote rapid myelin clearance and effective axon regeneration after nerve injury. Proc Natl Acad Sci U S A 2010, 107:11993-11998.

70. Hikawa N, Takenaka T: Myelin-stimulated macrophages release neurotrophic factors for adult dorsal root ganglion neurons in culture. Cell Mol Neurobiol 1996, 16:517-528.

71. Kigerl KA, Gensel JC, Ankeny DP, Alexander JK, Donnelly DJ, Popovich PG: Identification of two distinct macrophage subsets with divergent effects causing either neurotoxicity or regeneration in the injured mouse spinal cord. J Neurosci 2009, 29:13435-13444.

72. Lu D, Goussev A, Chen J, Pannu P, Li Y, Mahmood A, Chopp M: Atorvastatin reduces neurological deficit and increases synaptogenesis, angiogenesis, and neuronal survival in rats subjected to traumatic brain injury. J Neurotrauma 2004, 21:21-32.

73. Pannu R, Barbosa E, Singh AK, Singh I: Attenuation of acute inflammatory response by atorvastatin after spinal cord injury in rats. J Neurosci Res 2005, 79:340-350.

74. Angelov DN, Waibel S, Guntinas-Lichius O, Lenzen M, Neiss WF, Tomov TL, Yoles E, Kipnis J, Schori H, Reuter A, Ludolph A, Schwartz M: Therapeutic vaccine for acute and chronic motor neuron diseases: implications for amyotrophic lateral sclerosis. Proc Natl Acad Sci U S A 2003, 100:4790-4795.

75. Sicotte M, Tsatas O, Jeong SY, Cai CQ, He Z, David S: Immunization with myelin or recombinant Nogo-66/MAG in alum promotes axon regeneration and sprouting after corticospinal tract lesions in the spinal cord. Mol Cell Neurosci 2003, 23:251-263.

76. Huang DW, McKerracher L, Braun PE, David S: A therapeutic vaccine approach to stimulate axon regeneration in the adult mammalian spinal cord. Neuron 1999, 24:639-647.

77. Wolf SA, Fisher J, Bechmann I, Steiner B, Kwidzinski E, Nitsch R: Neuroprotection by T-cells depends on their subtype and activation state. J Neuroimmunol 2002, 133:72-80.

78. Aarli JA: Role of cytokines in neurological disorders. Curr Med Chem 2003, 10:1931-1937.

79. Dahle C, Ekerfelt C, Vrethem M, Samuelsson M, Ernerudh J: T helper type 2 like cytokine responses to peptides from P0 and P2 myelin proteins during the recovery phase of Guillain-Barre syndrome. J Neurol Sci 1997, 153:54-60.

80. Inoue A, Iwahashi T, Koh CS, Yanagisawa N: A study on subpopulation of helper T cells in chronic inflammatory demyelinating polyneuropathy. Arerugi 1994, 43:1270-1276

81. Deretzi G, Pelidou SH, Zou LP, Quiding C, Zhu J: Local effects of recombinant rat interleukin-6 on the peripheral nervous system. Immunology 1999, 97:582-587.

82. Malandrini A, Villanova M, Dotti MT, Federico A: Acute inflammatory neuropathy in Charcot-Marie-Tooth disease. Neurology 1999, 52:859-861.

83. Shy ME, Arroyo E, Sladky J, Menichella D, Jiang H, Xu W, Kamholz J, Scherer SS: Heterozygous PO knockout mice develop a peripheral neuropathy that resembles chronic inflammatory demyelinating polyneuropathy (CIDP). J Neuropathol Exp Neurol 1997, 56:811-821.

84. Schmid CD, Stienekemeier M, Oehen S, Bootz F, Zielasek J, Gold R, Toyka KV, Schachner M, Martini R: Immune deficiency in mouse models for inherited peripheral neuropathies leads to improved myelin maintenance. J Neurosci 2000, 20:729-735.

85. Carenini S, Maurer M, Werner A, Blazyca H, Toyka KV, Schmid CD, Raivich G, Martini R: The role of macrophages in demyelinating peripheral nervous system of mice heterozygously deficient in p0. J Cell Biol 2001, 152:301-308.

86. Qiu J, Cai D, Dai H, McAtee M, Hoffman PN, Bregman BS, Filbin MT: Spinal axon regeneration induced by elevation of cyclic AMP. Neuron 2002, 34:895-903.

87. Kuo HS, Tsai MJ, Huang MC, Chiu CW, Tsai CY, Lee MJ, Huang WC, Lin YL, Kuo WC, Cheng H: Acid fibroblast growth factor and peripheral nerve grafts regulate Th2 cytokine expression, macrophage activation, polyamine synthesis, and neurotrophin expression in transected rat spinal cords. J Neurosci 2011, 31:4137-4147.

88. Lee YS, Hsiao I, Lin WW: Peripheral nerve grafts and aFGF restore partial hindlimb function in adult paraplegic rats. J Neurotrauma 2002, 19:1203-1216 
89. Kaji R, Kiyoshima-Shibata J, Nagaoka M, Nanno M, Shida K: Bacterial teichoic acids reverse predominant IL-12 production induced by certain lactobacillus strains into predominant IL-10 production via TLR2dependent ERK activation in macrophages. J Immunol 2010, 184:3505-3513.

90. Redecke V, Hacker H, Datta SK, Fermin A, Pitha PM, Broide DH, Raz E: Cutting edge: activation of Toll-like receptor 2 induces a Th2 immune response and promotes experimental asthma. J Immunol 2004, 172:2739-2743.

doi:10.1186/1742-2094-9-176

Cite this article as: Ydens et al: Acute injury in the peripheral nervous system triggers an alternative macrophage response. Journal of Neuroinflammation 2012 9:176.

\section{Submit your next manuscript to BioMed Central and take full advantage of:}

- Convenient online submission

- Thorough peer review

- No space constraints or color figure charges

- Immediate publication on acceptance

- Inclusion in PubMed, CAS, Scopus and Google Scholar

- Research which is freely available for redistribution 